\title{
Current Medical Approach to Thyroid Stimulating Hormone-secreting Pituitary Adenomas
}

Thyroid stimulating hormone (TSH)-secreting pituitary adenomas are rare and comprise less than $1 \%$ of all pituitary tumors $(1,2)$. Despite its rare occurrence, the disease is important for internists as it causes hyperthyroidism and it can be managed medically. The signs and symptoms of hyperthyroidism may not lead to the diagnosis of a TSH-secreting adenoma, as the hyperthyroidism is mild in most of the cases and it is complicated with a variety of symptoms of pituitary tumors such as headache, optical disturbances, hypogonadism and/or infertility. The diagnosis of TSH-secreting pituitary adenomas can be made only by confirming the characteristic finding of increased thyroid hormone levels with non-suppressed TSH, the so-called "inappropriate secretion of TSH (ISTSH)" where a negative feedback mechanism is not operating normally. Non-suppressed or detectable TSH is the most critical distinction to differentiate TSH-mediated hyperthyroidism from Graves' disease as Fukuda et al (3) described in this issue of Internal Medicine.

See also p 1027.

It must be emphasized that the development of the ultrasensitive TSH assay made the differential diagnosis easier (4), and the number of reported cases has increased thereafter (5). Failure to respond to thyrotropin-releasing hormone (TRH) stimulation or to triiodothyronine (T3) suppression test, or an increased molar ratio of $\alpha$ subunit to intact TSH are supportive but adjunctive to differentiate the disease from "pituitary resistance to thyroid hormone", another rare disease with ISTSH. The final diagnosis of TSH-secreting pituitary adenomas can be made by confirming the presence of pituitary tumors by means of pituitary imaging, computed tomography (CT) scan or magnetic resonance imaging (MRI).

What is the current therapeutic strategy for TSH-secreting pituitary adenomas? Surgical removal should be the first choice for growth hormone $(\mathrm{GH})$ - or adrenocorticotropic hormone (ACTH)-secreting adenomas. The outcome of the surgery is not satisfactory for TSH-secreting tumors as most of them are macroadenomas $(5,6)$. Fortunately, we have several medical maneuvers to manage hormone secretion and/or tumor growth. Antithyroid drugs or radioiodine were initially used to control hyperthyroidism. Then, bromocriptine, a long-acting dopamine agonist was introduced for the treatment of TSH-secreting adenomas based on its outstanding effects for most of prolactinomas or some $\mathrm{GH}$ adenomas.

Contrary to our expectation, it turned out that long-term bromocriptine therapy was not effective for TSH-secreting adenomas because of incomplete suppression or rebound elevation of TSH $(1,2)$. At present, we have a potent alternative, "octreotide". In contrast to bromocriptine, most TSH-secreting adenomas respond to somatostatin (7) and its long-acting analogue, octreotide $(1,5,8,9)$. TSH levels returned to normal in $2 / 3(8,9)$ or $90 \%(5)$ and the tumor size was reduced in $1 / 3$ $(8,9)$ or $45 \%(5)$ of the reviewed literature cases of TSHsecreting adenomas treated by octreotide using the typical daily dose of $100-500 \mu \mathrm{g}$. Tahyphylaxis was seldom reported. A varying response to octreotide may be due to the heterogenous distribution of somatostatin receptor among TSH adenomas (10). In vitro studies have demonstrated certain numbers of somatostatin receptors with various affinities (11). A good correlation was reported between the uptake and TSH suppression in TSH-secreting adenomas by octreotide scintigraphy (12). Thus, octreotide is the most promising medical tool for a treatment of patients with TSH-secreting pituitary adenomas who refuse surgery or who are poor surgical candidates as Fukuda et al (3) presented in this issue of Internal Medicine. Radiotherapy and/or antithyroid drugs may be the final candidate for non-responders to octreotide.

\section{Reiko DEMURA, MD The Department of Internal Medicine, Institute of Clinical Endocrinology, Tokyo Women's Medical University, 10-22 Kawada-cho, Shinjuku-ku, Tokyo 162-8666 \\ References}

1) Smallidge RC. Thyrotropin-secreting pituitary tumors. Endocrinol Metab Clin North Am 16: 765-792, 1987.

2) Greenman $Y$, Melmed $S$. Thyrotropin-secreting pituitary tumors. In: The Pituitary, Melmed S, Ed. Blackwell Sci Inc, Boston, 1995: 546-558.

3) Fukuda T, Yokoyama N, Tamai M, et al. Thyrotropin secreting pituitary adenoma effectively treated with octreotide. Intern Med 37: 1027-1030 1998.

4) Spencer CA, LoPresti JS, Patel A, et al. Applications of a new chemiluminometric thyrotropin assay to subnormal measurement. J Clin Endocrinol Metab 70: 453-460, 1990.

5) Beck-Peccoz P, Persani L. TSH adenomas: Clinical findings, endocrinology, treatment. In: Pituitary Adenomas, Landolt AM, Vance ML, Reilly PL Eds. Churchill Livingstone, New York, 1996: 139-155.

6) McCutcheon IE, Weintraub BD, Oldfield EH. Surgical treatment of thyrotropin-secreting pituitary adenomas. J Neurosurg 73: 674-683, 1990.

7) Reschini E, Giustina G, Cantalamessa L, Lperacchi M. Hyperthyroidism with elevated plasma TSH levels and pituitary tumors. Study with somatostatin. J Clin Endocrinol Metab 43: 924-927, 1976. 
8) Chanson P, Weintraub BC, Harris AG. Octreotide therapy for thyroidstimulating hormone-secreting pituitary adenomas. A follow-up of 52 patients. Ann Int Med 119: 236-240, 1993.

9) Chanson P, Warnet A. Treatment of thyroid-stimulating hormone-secreting adenomas with octreotide. Metabolism 41: 62-65, 1992.

10) Bertherat J, Brue T, Enjalbert A, et al. Somatostatin receptors on thyrotropin-secreting pituitary adenomas: comparison with the inhibitory effects of octreotide upon in vivo and in vitro hormonal secretions. J Clin
Endocrinol Metab 75: 540-546, 1992.

11) Boni G, Ferdeghini M, Bellina CR, et al. [111In-DTPA-D-Phe]-octreotide scintigraphy in functioning and non-functioning pituitary adenomas. Q J Nucl Med 39: 90-93, 1995.

12) Losa $M$, Magnani $P$, Mortini $P$, et al. Indium-111 pentetreotide singlephoton emission tomography in patients with TSH-secreting pituitary adenomas: correlation with the effect of a single administration of octreotide on serum TSH levels. Eur J Nucl Med 24: 728-731, 1997. 